\title{
No barrier at the boundaries: implementing regional frameworks for noise management in protected natural areas
}

\author{
Leila T. Hatch ${ }^{1, *}$, Kurt M. Fristrup ${ }^{2}$ \\ ${ }^{1}$ Gerry E. Studds Stellwagen Bank National Marine Sanctuary, National Oceanic and Atmospheric Administration, \\ 175 Edward Foster Road, Scituate, Massachusetts 02066, USA \\ ${ }^{2}$ Natural Sounds Program Center, National Park Service, 1201 Oakridge Drive, Suite 100, Fort Collins, \\ Colorado 80525-5596, USA
}

\begin{abstract}
We compare the status of regional or ecosystem frameworks for managing airborne and underwater noise sources in the US, with particular emphasis on transportation noise in national marine sanctuaries and national parks. The Organic Act demands that the US National Park Service (NPS) preserve natural and cultural resources unimpaired for future generations, and NPS policies provide explicit guidance for managing acoustical environments to meet this standard. The US Office of National Marine Sanctuaries identifies noise as a threat to sanctuary resources, but does not address how the program should manage noise levels to minimize impacts to wildlife and protect the aesthetic resources within sanctuaries. Methods and results from 2 case studies that address noise management in spatially explicit contexts are highlighted: the Gerry E. Studds Stellwagen Bank National Marine Sanctuary and the Grand Canyon National Park. In both case studies, noise generated by transportation networks that extend far beyond protected area boundaries must be managed to conserve local resources. Effective noise control policies must be developed through partnerships among transportation and resource management agencies, surmounting differences in their missions, professional cultures, and historical precedents. Four collective approaches for managing noise in protected natural areas emerge from this analysis: (1) investing in monitoring programs and data management; (2) expanding the resolution and scope of impact assessment tools; (3) enhancing coordination and the governance structure; and (4) engaging and educating US citizens regarding the benefits of quieting.
\end{abstract}

KEY WORDS: Noise $\cdot$ Ecosystem-based management $\cdot$ National marine sanctuaries $\cdot$ National parks . Environmental impacts $\cdot$ Conservation

\section{INTRODUCTION}

'Fortunately, nature has a few big places beyond man's power to spoil — the ocean, the two icy ends of the globe, and the Grand Cañon' (Muir 1902).

The pervasive growth of noise exposure in marine and terrestrial environments affects animals' ability to sustain acoustical surveillance of their surroundings, and poses risks of profound ecological change. Hearing is an incessant, omnidirectional sense, while vision is largely intentional and directed. Differentiation between these roles is magnified underwater due to the greater efficiency of transmission of sound relative to light in water. Many events can be heard at greater ranges than they can be seen. There are large gaps in the coverage of the visual field. Hearing extends animal awareness under all conditions, and is essential when vision is compromised.

Animals maintain constant auditory vigilance, and can awaken from sleep or torpor in response to sounds. 
Sound events that do not wake sleeping humans can, nonetheless, cause physiological arousal, and may have long-term health effects (Spreng 2000, Babisch 2006, Wright et al. 2007, Haralabidis et al. 2008). Noise presents at least 4 threats: diversion of attention and disruption of behavior, habituation or 'learned deafness', masking of important signals, and spurious physiological stimulation. These threats present several costs: compromised physiological function, diversion of time and energy, failure to detect important cues, impaired acoustical advertisement and communication, and reduced utilization of important habitats or resources. All of these costs have consequences for fitness.

Vitousek et al. (1997) and Halpern et al. (2008) did not include noise in their reviews of pervasive human impacts; nevertheless, enormous areas of the globe experience degraded acoustical conditions due to noise. Although terrestrial vehicles and aircraft are more numerous and faster than sea-going vessels, sound propagates with much lower absorption underwater, leading to larger noise footprints. Accordingly, the spatial and temporal dimensions of noise pollution problems are strikingly similar on land and beneath the waves. Human activities are the dominant sources of acoustic energy at many sites in both environments (reviewed by Richardson et al. 1995, NRC 2000, Miller 2003). Concerns regarding the impacts of these sounds on terrestrial and marine wildlife have focused primarily on high power, short-duration sources (e.g. Côté 1996, NRC 2000, Frid 2003, MMC 2007, Nowacek et al. 2007, Southall et al. 2007). However, impacts from lower intensity, chronic noise sources have also been identified as problematic (Payne \& Webb 1971, Southall 2005, Rabin et al. 2006, Habib et al. 2007, Hatch et al. 2008, Southall \& Scholik-Schlomer 2009). In areas with high rates or levels of noise-producing human activities, listening horizons are significantly reduced by elevated background sound levels (NRC 2005, Clark et al. 2009, this Theme Section). Even in the world's quietest places, the intervals between noise events are diminishing.

Reports addressing impacts to wildlife due to noise exposure have recommended the utilization of regionally focused or ecosystem-based management tools (Grumbine 1994, NRC 2003, McCarthy 2004, NRC 2005, Weilgart 2006, Agardy et al. 2007, Dolman 2007 , Van Parijs \& Southall 2007, Hatch et al. 2008). This study compares the status of regional or ecosystem frameworks for managing airborne and underwater noise sources in US parks and sanctuaries. The comparison addresses the evolution of science and policy supporting regional or ecosystem noise management frameworks, followed by 2 case studies that illustrate their implementation: the Gerry E. Studds Stellwagen Bank National Marine Sanctuary, and the Grand
Canyon National Park. The similarities and differences in management in marine and terrestrial realms are summarized, outstanding scientific and policy gaps identified, and interim approaches to ecosystem management frameworks recommended.

\section{REVIEW OF CURRENT POLICY AND SCIENCE SUPPORTING REGIONAL NOISE MANAGEMENT}

\section{Marine}

Human activities generate sound in the marine environment for explicit purposes (e.g. mapping or exploration), and as an incidental byproduct of industrial activities (e.g. construction or transportation). Incidental noise generated by ships contributes significantly to low-frequency ambient sound levels in the ocean (Richardson et al. 1995). Low-frequency ambient noise has increased at an average of $3 \mathrm{~dB}$ decade ${ }^{-1}$ over the past $50 \mathrm{yr}-\mathrm{a}$ 32-fold increase in overall noise energy - in many northern hemisphere locations such as the west coast of the US (Andrew et al. 2002, McDonald et al. 2006, Andrew et al. in press).

The global commercial shipping fleet expanded from $\sim 30000$ vessels ( 85000 000 gross tons) in 1950 to over 85000 vessels ( 525000 000 gross tons) in 1998 (NRC 2003). Ships are the most economical means of bulk transport (United Nations 2008). It has been calculated that $>90 \%$ of world trade (in gross tonnage) goes by ship, with world seaborne trade increasing by $38 \%$ (to 5 billion tons) between 1985 and 1999 (ibid.). The certainty of further escalation in anthropogenic contributions to ambient ocean noise has elevated concerns regarding impacts to marine wildlife (Southall 2005, Hatch et al. 2008, Hester et al. 2008, Tyack 2008, Southall \& Scholik-Schlomer 2009, Clark et al. 2009).

The legislative basis for most undersea noise regulation in US waters focuses on the protection and recovery of particular species. Under the US Endangered Species Act (ESA) (ESA 1973 as amended through 2004), acoustic injury or disturbance of any listed marine species or population is considered when determining if a proposed action will 'jeopardize' the species' or population's continued existence. In addition, ESA consultations may consider whether the noise produced by the proposed action will result in the destruction or adverse modification of listed species' critical habitats. Under the US Marine Mammal Protection Act (MMPA) (MMPA 1972 as amended through 2007), authorizations are required for human activities that could acoustically harass marine mammals. Harassment, for all activities other than military readiness activities, is defined under the MMPA as 'any act of pursuit, torment, or annoyance which has 
the potential to injure a marine mammal or marine mammal stock in the wild, or has the potential to cause disruption of behavioral patterns, including, but not limited to, migration, breathing, nursing, breeding, feeding, or sheltering' (ibid., Section 3.18). Exposure thresholds have been established by the US National Oceanic and Atmospheric Administration's (NOAA's) National Marine Fisheries Service to identify potential noise impacts to marine mammals. For impacts to cetaceans (whales and dolphins) exposed to sequences of pulsed sounds, the threshold associated with harassment is $160 \mathrm{~dB}$ re $1 \mu \mathrm{Pa}$ at $1 \mathrm{~m}$; for continuous sounds, the threshold is reduced to $120 \mathrm{~dB}$ re $1 \mu \mathrm{Pa}$ at $1 \mathrm{~m}$. For pinnipeds (seals and sea lions), the corresponding harassment thresholds are $180 \mathrm{~dB}$ re $1 \mu \mathrm{Pa}$ at $1 \mathrm{~m}$ for sequences of pulsed sounds, and $160 \mathrm{~dB}$ re $1 \mu \mathrm{Pa}$ at $1 \mathrm{~m}$ for continuous sounds (NOAA 2005, 50 CFR 216). These coarse distinctions between cetaceans and pinnipeds understate the variation in the species' sensitivities to noise and aim for conservative levels of protection for species where scientific uncertainty is high.

Both applicants who seek authorization to engage in activities that may cause injury or harassment to marine mammals, and resource managers who evaluate noise impacts to endangered species, must develop estimates of the number of individuals that will be exposed to specified noise levels. These estimates incorporate knowledge or assumptions regarding the sound source characteristics, propagation conditions, and the location and movements of individual animals (Siderius \& Houser 2006).

Relatively few software packages integrate all significant determinants of noise exposure in a flexible model that can be applied to any marine setting. Researchers at Marine Acoustics developed the Acoustic Integration Model (AIM) to estimate sound exposure histories experienced by mobile animals in the vicinity of stationary or moving sound sources (Frankel et al. 2003). AIM incorporates regional and seasonal behavioral data for each species, oceanographic databases, and the radiative characteristics of the sound source. Users can choose among several propagation models, and predict the effects of different operational scenarios at multiple animal response levels (ibid.). AIM accounts for variation in both acoustic propagation and sound exposure levels as a function of depth as well as range, thus allowing animal behavior, including responses to environmental variables, to affect individual exposure histories. AIM algorithms were initially developed to assess environmental impacts associated with the US Navy's use of low frequency active sonar and have since been utilized in a variety of planning, environmental assessment and research contexts. In addition to reviews associated with these applications and publications in peer-reviewed literature, AIM has been independently reviewed by the Center for Independent Experts (CIE) (CIE 2006).

The US Navy initiated the Effects of Sound on the Marine Environment (ESME) program (Shyu \& Hillson 2006) to build and test a modular software tool for evaluating environmental impacts associated with soundproducing activities. ESME is being developed to utilize several components focused on marine mammals (e.g. hearing abilities, behavioral responses to sound, and distribution and abundance), sound sources and their transmission environments, and numerical techniques for propagation modeling.

Additional tools for combining acoustic propagation models and animal density data have been developed and patented by researchers at the Naval Undersea Warfare Center (NUWC) (Lazauski et al. 2003). Propagation loss calculations in the NUWC model are performed by the Comprehensive Acoustic Simulation System/Gaussian Ray Bundle (Aidala et al. 1998, Keenan 2000, Weinberg et al. 2001). The NUWC model has been subjected to numerous revisions and upgrades since its initial release in 1999 (Lazauski et al. 1999). The current model is capable of analyzing both moving and stationary sources and calculating acoustic propagation profiles and received energy levels as a function of range and depth while producing exposure estimates. NUWC modelers have also worked with ESME developers to integrate ESME's marine mammal components into the NUWC model. Thus, the current NUWC model has the capability of simulating the movement and responses of animals to their acoustic environment (Jette et al. 2005). This model is currently being applied to assess environmental impacts associated with the US Navy's use of active sonar in a variety of contexts. It has been peer reviewed as a technical report and is scheduled for independent review by CIE in 2009.

The above software packages have primarily been applied within the scope of the MMPA's permitting authority. Thus, they have been used to predict the number of animals that are likely to be exposed to noise levels that could result in injury or harassment within the context of activities that are proposed by US citizens, limited to specified geographical regions and limited to relatively short periods of time (under $5 \mathrm{yr}$ ). These spatial and temporal limits coincide with the scope of MMPA's permitting authority (MMPA 1972 as amended through 2007). Each permit requires several months of processing by NOAA staff (incorporating information collected during public comment periods) to determine the extent of impacts and the mitigation, monitoring, and reporting needed to ensure that the levels of impact to each species are negligible. A codified framework for analysis at these spatial and temporal scales is emerging, although 
NOAA's thresholds for injury and harassment have not been consistently applied in US regulatory actions (Southall et al. 2007).

Transiting vessels are conspicuously exempt from noise exposure assessment and regulation. Transiting vessels introduce a variety of exposure patterns. Dispersed vessel traffic will produce transient noise peaks for those animals close to each ship's path. Shipping lanes generate similar transient peaks, but at much higher repetition rates. Finally, the integrated effects of numerous distant vessels create a slowly varying background noise level that is omnipresent.

Significant challenges remain in accounting for cumulative impacts to individual species and extending analyses over spatial scales pertinent to most protected or listed marine animals and many types of underwater noise, including vessel noise. Chronic exposure to noise, whether from continuous sources or repeated, intermittent noise events, is rarely taken into account in modeling. It is unclear whether the MMPA's harassment provisions provide an appropriate accounting for potential impacts at larger spatial and longer temporal scales, or whether it is practical to apply current software tools at these scales. The burden of collecting the input data needed for these models and simulating animal impacts on an individual basis may be excessive. Moreover, this level of precision may be excessive, and may provide a misleading impression of accuracy. Vessel noise regulation under the MMPA also faces jurisdictional challenges, as the majority of large vessels that operate in US waters are owned and operated by foreign nationals.

Beyond the limitations imposed by the current regulatory process and scope, a variety of reports have identified context-driven shortcomings associated with applying a species-by-species and source-by-source approach to noise control in the ocean (e.g. NRC 2005, MMC 2007, Southall et al. 2007). Software packages designed primarily to calculate accrued exposure of focal animals do not reflect relationships between different focal species (such as different whale species) or between focal and nonfocal species (such as marine mammals and their prey). Indirect effects of noise exposure resulting from interspecific interactions are not taken into account. Impact assessments based on these analyses are often insufficient to meet additional mandates imposed by the MMPA and ESA, as well as those of the National Environmental Policy Act (NEPA 1969 as amended through 1982). These laws require NOAA to take into account cumulative impacts to protected or listed species and their habitats when authorizing acoustic harassment and evaluating noise impacts.

The US Council of Environmental Quality's regulations governing NEPA compliance define cumulative impacts as 'the impact on the environment which results from the incremental impact of the action when added to other past, present, and reasonably foreseeable future actions' (CEQ 1987). A US Environmental Protection Agency (EPA)-authored guidance document regarding NEPA and cumulative impacts further states that 'While impacts can be differentiated by direct, indirect, and cumulative, the concept of cumulative impacts takes into account all disturbances since cumulative impacts result in the compounding of the effects of all actions over time. Thus the cumulative impacts of an action can be viewed as the total effects on a resource, ecosystem, or human community of that action and all other activities affecting that resource no matter what entity (federal, nonfederal, or private) is taking the actions' (EPA 1999, Section 2).

It is generally acknowledged that cumulative impacts are not fully addressed in many NEPA documents due to seemingly insuperable complexities and gaps in scientific data, and pragmatic decisions to circumscribe the scope and size of the documents (CEQ 1997, EPA 1999).

Several authors have recommended developing the use of area-based management tools, such as the US National Marine Sanctuaries Act, to assess and address human-induced underwater noise more holistically in places designated to be of national concern (NRC 2003, McCarthy 2004, NRC 2005, Weilgart 2006, Agardy et al. 2007, Dolman 2007, Van Parijs \& Southall 2007, Hatch et al. 2008). In 1992, comprehensive amendments to the Marine Protection, Research, and Sanctuaries Act of 1972, led Title III to be renamed the National Marine Sanctuaries Act (NMSA) (NMSA 1992 as amended through 2000). As established under the NMSA, the US Office of National Marine Sanctuaries (ONMS), which is part of NOAA, manages a national system of 13 sanctuaries and co-manages a single national marine monument. Although several local, state and federal agency branches or other management authorities aimed at protecting specific marine resources may have overlapping regulations, the ONMS' mandate to comprehensively conserve and manage designated areas of the marine environment is unique under US law.

The initial legislative intent for creating marine sanctuaries in US waters was clearly preservationist, and aimed at mimicking terrestrial protection provided for wilderness areas under the Wilderness Act or National Parks under the Organic Act (Owen 2003, Chandler \& Gillelan 2004). However, by the time the NMSA's precursor was passed, multi-use principles, similar to those used to manage nonwilderness areas of the National Forest System, had gained prominence (Owen 2003). The history of designating national marine sanctuaries has continued to reflect divergent 
regional and national values regarding ocean use and protection. Currently, the NMSA prevents new site designations based on limited funding and oscillates between multi-use and preservation priorities (Owen 2003, Chandler \& Gillelan 2004). Management priorities are to be reconciled by determining the compatibility of human activities with preventing injury to sanctuary resources (NMSA 1992 as amended through 2000). The NMSA identifies resources to be characterized relative to their threats as 'any living or nonliving resource of a national marine sanctuary that contributes to the conservation, recreational, ecological, historical, educational, cultural, archaeological, scientific, or aesthetic value of the sanctuary' (ibid., Section 302(8)). In a recent policy statement, the ONMS asserted both the inclusion of human-induced noise in characterizations of threats to sanctuary resources, and its commitment to preventing and/or mitigating such threats as necessary and appropriate through both voluntary and regulatory means (NOAA 2007a). Thus, in national marine sanctuaries, acoustic impacts are to be assessed on an ecosystem rather than a species-specific basis. In defining ecosystem-based management for the oceans, a scientific consensus statement explained the following: 'Ecosystem-based management differs from current approaches that usually focus on a single species, sector, activity or concern; it considers the cumulative impacts of different sectors. Specifically, ecosystem-based management: emphasizes the protection of ecosystem structure, functioning, and key processes; is place-based in focusing on a specific ecosystem and the range of activities affecting it; explicitly accounts for the interconnectedness within systems, recognizing the importance of interactions between many target species or key services and other nontarget species; acknowledges interconnectedness among systems, such as between air, land and sea; and integrates ecological, social, economic, and institutional perspectives, recognizing their strong interdependences' (McLeod et al. 2005).

The above approach is entirely consistent with the policies and purposes of the NMSA, which provides authority 'for comprehensive and coordinated conservation and management of these marine areas, and activities affecting them, in a manner which complements existing regulatory authorities...' (NMSA 1992 as amended through 2000, Section 301(b)). This mandate calls for ecosystem-based management within sanctuaries and intensive collaboration with other agencies responsible for managing ecosystem components both within and beyond sanctuary boundaries.

Sanctuaries do not encompass entire ecosystems, but are portions of ecosystems delineated by congressionally designated geographic boundaries. Within these boundaries, environmental stressors caused by humans and natural events can be examined, monitored, evaluated, and managed (NOAA 2008). The NMSA provides a tool for assessing the comprehensive impacts of human-induced noise on local marine environments which, in turn, could drive the promulgation of regulations to reduce noise exposure. Paired with international initiatives to develop environmental best practices for commercial shipping, localized quieting and noise control could ensure that the sanctuary soundscapes, as resources in and of themselves, are protected from injury.

\section{Terrestrial}

Commercial air freight and passenger transportation are the terrestrial analog to shipping noise in the ocean. The noise footprint of an individual jet on land is smaller than a tanker in most ocean environments, but in the quietest areas of the western US, a high altitude jet can be audible $32 \mathrm{~km}$ or more from the source. Although sound can travel much farther in the ocean, the pervasive character of aircraft noise derives from the number, speed, and spatial extent of the operations. There are over 7500 aircraft in the commercial airline passenger and freight transport fleets, and over 11000 aircraft in the commuter air carrier and air taxi fleet (US Federal Aviation Administration, FAA 2008). For the 9 mo period from January through September 2007, FAA Air Traffic Control Centers handled over 35 million flights (air carrier, air taxi, general aviation, and military), for an average of $\sim 130000$ flight operations $\mathrm{d}^{-1}$ (ibid.). Miller (2003) estimated the fraction of each county in which aircraft noise would be noticeable for the continental US. This model utilized flight tracks from a single hour of departures (15:00 to 16:00 h on 17 October 2000). The study found that aircraft noise from these flights would be noticeable in $>50 \%$ of the area in most counties, with most exceptions being the densely populated counties where local noise sources mask aircraft sounds (Miller 2003).

Transportation noise from roads is also pervasive and increasing rapidly. Between 1970 and 2007, the traffic on US roads nearly tripled to almost 5 trillion vehicle $\mathrm{km} \mathrm{yr}^{-1}$ (US Federal Highway Administration 2008). The US population increased by $\sim 1 / 3$ in the same time span (US Census Bureau 2008). Most traffic is concentrated in urban centers and along interstate highways, but a large fraction of the nation is within the noise envelope of a road. Riitters \& Wickham (2003) estimated that $97 \%$ of the land area within the coterminous US is within $5176 \mathrm{~m}$ of a road. An average passenger vehicle radiates $\sim 68 \mathrm{~dB}(\mathrm{~A})$ at a $7.5 \mathrm{~m}$ distance (Miller 1982), and $5 \mathrm{~km}$ represents a plausible limit of 
audibility for this sound source under the best listening conditions. Note that motorcycles, all-terrain vehicles, large trucks, and snowmobiles are substantially louder than automobiles.

Humans share terrestrial environments with wildlife, so we have a more direct basis for understanding the potential impacts of airborne noise on other species. All vertebrates sense sound using homologous organs and neural mechanisms. It is inevitable that noise management practices for wildlife will be influenced, and hopefully informed, by human responses to noise. However, the foci of community noise management have been health impacts (mainly hearing loss) and annoyance. Outside of architectural acoustics, the concept of preserving high quality acoustic environments has been neglected until very recently.

The US Noise Control Act (NCA 1972) gave the EPA the primary role of assessing noise impacts to human health and welfare, and coordinating noise management activities by federal agencies. Although this statute is still in force, funding for the Office of Noise Abatement and Control at EPA was terminated in 1981. The Reagan Administration and Congress asserted that noise regulation was best handled at the state and local levels. This action hampered the development of a national noise policy. Of the 28 federal environmental, health, and safety statutes enacted between 1958 and 1980, the NCA is the only one without budgetary support (Shapiro 1991). In 2003, escalating community noise levels and evidence that the US was lagging behind other nations in noise management prompted a special issue of the Noise Control Engineering Journal. This diverse collection of articles forcefully asserted the need for a new national noise policy (Holger 2003).

The US National Park Service (NPS) is charged with providing park visitors with outstanding opportunities to enjoy and appreciate natural and cultural resources, and preserving those resources unimpaired for the enjoyment of future generations (NPS Organic Act 1916). The acoustical implications of this mandate are spelled out in the NPS's 2006 Management Policies:

'The Service will take action to prevent or minimize all noise that through frequency, magnitude, or duration adversely affects the natural soundscape ${ }^{1}$ or other park resources or values, or that exceeds levels that have been identified through monitoring as being acceptable to or appropriate for visitor uses at the sites being monitored' (NPS 2006, section 4.9).

\footnotetext{
19lthough NPS used 'soundscape' to refer to physical resources in the 2006 policies, the NPS Natural Sounds Program finds it increasingly useful to distinguish between a visitor's immersive listening experience - the soundscape and the acoustic resources (the physical phenomena)
}

The reference condition for NPS management is clearly specified to be the historical, noise-free environment (NPS 2006, section 8.2.3): 'The natural ambient sound level-that is, the environment of sound that exists in the absence of human-caused noise - is the baseline condition, and the standard against which current conditions in a soundscape will be measured and evaluated.'

The NPS has several regulations for managing noise in park units. The most general regulation addresses audio disturbances, which cannot exceed a noise level of $60 \mathrm{~dB}(\mathrm{~A})$ at a distance of $15 \mathrm{~m}$ from the source, or 'noise which is unreasonable, considering the nature and purpose of the actor's conduct, location, time of day or night, purpose for which the area was established, impact on park users, and other factors that would govern the conduct of a reasonably prudent person under the circumstances' (NPS 2008a, 36 CFR 2.12 and 2.34). This regulation applies to motorized equipment, audio devices, and motor vehicles. Visitors also cannot allow a pet to make unreasonable noise, including noise that frightens wildlife (ibid., 36 CFR 2.15). Snowmobiles used in parks cannot exceed $82 \mathrm{~dB}(\mathrm{~A})$ at $15 \mathrm{~m}$ distance (ibid., 36 CFR 2.18). Lastly, airborne noise from boats may not exceed $75 \mathrm{~dB}(\mathrm{~A})$ at $15 \mathrm{~m}$ (ibid., 36 CFR 3.15). The development of these regulations was not coordinated; vehicles that operate in conditions that enhance long-range sound propagation are permitted to be louder (i.e. one snowmobile is allowed to make as much noise as 158 automobiles; one boat is allowed the same noise as 32 automobiles). The snowmobile and boat regulations were heavily influenced by industry product standards.

It is significant that the NPS regards noise as an impact to acoustic resources, independent of any consequences for wildlife or park visitors. Director's Order \#47 (NPS 2000) requires every park unit to develop a soundscape management plan to ensure the preservation of acoustic resources. These policies clearly declare very protective standards for noise management, in stark contrast to community noise practices based on maximum tolerable noise levels (Fidell 2003). Road projects trigger environmental reviews of noise impacts to adjacent parks and protected natural areas (US Department of Transportation Act 1966 as amended through 1968, section 4(f)). Airport projects undergo the same kind of environmental review as roads, with noise from aircraft operations at $>10000$ feet above ground level being categorically excluded from noise impact analysis (FAA 2006, section 14.5e).

Three pieces of federal legislation have addressed the management of aircraft noise in national parks. The quality of acoustic environments was specifically referenced in the US Grand Canyon National Park Enlargement Act (GCNPEA 1975, Section 8), which 
recognized 'natural quiet as a value or resource in its own right to be protected from significant adverse effect.' This Act also required the NPS to determine whether aircraft overflights were causing 'significant adverse effect on the natural quiet and experience of the park.' Subsequently, the US National Parks Overflight Act (NPOA 1987) and the US National Parks Air Tour Management Act (NPATMA 2000) required management plans for all parks with air tours, except for parks in Alaska. No plan has been completed to date. The NPS and the FAA have disagreed about noise assessment methodology and jurisdiction over determinations of impact, echoing the interagency disputes between EPA and FAA regarding noise assessments in the 1970s (Malings 2003).

Fortunately, there has been more progress on technical issues. The FAA and the NPS have agreed upon acoustical monitoring protocols and methods for analyzing these data to produce statistical summaries. Acoustical monitoring provides an inventory of current conditions, which can be processed to characterize the native acoustic environment in the absence of extrinsic noise sources. It is impractical to monitor all sites of interest, so the FAA and the NPS have developed sampling plans for monitoring that address the needs of air tour management plans and provide information that may apply to other parks and other management issues. Current sampling designs incorporate information regarding seasonal and spatial coverage, topography, vegetation zones, wildlife distributions, and human activity patterns. For protected natural areas, the NPS and the FAA have agreed on a minimum of $25 \mathrm{~d}$ of continuous monitoring as necessary to document the range of acoustical conditions during one season. Most studies obtain samples in at least 2 seasons of the year - usually the seasons with the highest and the lowest activity.

In addition to gathering empirical data, acoustical modeling is used to assess the potential effects of noise from all major ground or air transportation projects in the US. The US Department of Transportation has designated 2 models as their standards for noise studies. The Traffic Noise Model (TNM) is used for road projects, and the Integrated Noise Model (INM) is used for aviation projects (www.volpe.dot.gov/acoustics/soft.html, accessed 15 May 2008). Both of these models are maintained by the Volpe National Transportation Systems Center (Cambridge, MA). These models treat segments of roads or aircraft routes as line sources of noise. They sum the contributions from these segments to compute aggregate noise metrics. Both models share a common treatment of many physical properties of sound propagation. However, they differ in their treatment of noise sources. TNM treats traffic as a statistical aggregate, characterized by its average speed, overall density (ve- hicles $\mathrm{h}^{-1}$ ), and composition in terms of the fraction of vehicles that are light and heavy trucks. The primary output of this model is the hourly A-weighted average intensity level ('equivalent level' or $L_{\text {eq }}$ ), specified in decibels (A-weighting expresses the decreased sensitivity of human hearing for sounds below $1 \mathrm{kHz}$ and above $6 \mathrm{kHz}$ ). INM analyzes the impacts of individual flights. This analysis identifies each unique combination of route, operating parameters, and aircraft type into 'flight types'. The noise contributions of these flight types are computed separately, and subsequently summed to predict overall noise exposure. The primary output of this model is the DNL ('day-night level') - a $24 \mathrm{~h}$ integral of A-weighted noise exposure that includes a $10 \mathrm{~dB}$ increase added to all nocturnal flight noise.

The NPS found that integrated noise metrics like the DNL and hourly $L_{\text {eq }}$ were difficult to relate to visitor experience, and were inadequate to meet legislative mandates to preserve resources unimpaired. Accordingly, the NPS focused on the audibility of noise sources, as quantified by percent time audible and noise-free interval statistics. In order to estimate audibility, noise models must utilize spectral information in their acoustical calculations. The NPS evaluated 2 noise models that provided this feature. INM was modified to enable prediction of audibility. The NoiseMap Simulation model (NMSim), which was developed by Wyle Laboratories, was based on extensive studies of the effects of topography on sound propagation around airfields. Unlike the integrative approach in TNM and INM, NMSim simulates the movement of individual noise sources, so it can produce animations of noise exposure to illustrate the spatiotemporal dynamics of aircraft and vehicle noise events. An empirical test of the accuracy of both models was performed at Grand Canyon. NMSim was found to be slightly more accurate, but INM had a more complete database of aircraft noise profiles (Miller et al. 2003, Fleming et al. 2005). To date, INM has been the only model used in FAA-NPS overflight noise assessments.

\section{CASE STUDIES}

\section{Marine}

Although the word 'sanctuary' has several definitions, it is most commonly used to refer to a sacred place of worship (Encyclopædia Britannica 2008). Thus, it is understandable that people conceive of marine sanctuaries as sharing properties with temples and altars, which are intrinsically quiet places. They are often surprised to learn that a variety of noisy activities occur within marine sanctuaries. The Gerry E. Studds Stellwagen Bank National Marine Sanctuary 
(SBNMS) has become a hub of research focused on evaluating the potential impacts of noise on marine ecosystems due to the high level of human activity and the fragility of species and habitats co-occurring within its boundaries.

The SBNMS is an 'urban' marine sanctuary adjacent to a high density coastal zone. SBNMS encompasses 638 nautical miles ${ }^{2}$ (nautical miles: $\mathrm{n}$ miles) of open water and seafloor at the mouth of Massachusetts Bay off the northeastern coast of the US. The International Maritime Organization (IMO)-approved Traffic Separation Scheme for the Port of Boston runs directly through the sanctuary in an east-west pattern, routing the daily transits of container ships, tankers carrying oil and liquefied natural gas (LNG), and cruise lines. Recently, 2 companies have received licenses to build and operate offshore LNG import terminals adjacent to the northwestern border of SBNMS. The sanctuary also hosts some of the oldest and highest capacity commercial fisheries in the world, with $\sim 40$ commercial vessels fishing in the SBNMS every year using mobile and fixed gear throughout the water column and on the seafloor. On a regional scale, the sanctuary is a part of the Gulf of Maine ecosystem, which is an important feeding ground for endangered marine mammals such as North Atlantic right whales (Eubalaena glacialis), humpback whales (Megaptera novaeangliae) and finback whales (Balaenoptera physalus) in addition to other marine mammal species (NOAA 2008). Approximately 1 million whale-watch passengers visit SBNMS each year, with 14 to 16 whale-watch boats making 1 to 3 visits $\mathrm{d}^{-1}$ in season (ibid.).

Since 2006, a collaborative group of researchers from the SBNMS - NOAA's Northeast Fisheries Science Center and Cornell University's Bioacoustics Research Program (BRP) - have been characterizing the acoustic environment and health of SBNMS using arrays of autonomous recording units (ARUs) to monitor low frequency $(10-1000 \mathrm{~Hz})$ underwater sounds throughout sanctuary waters (Hatch et al. 2008). To calculate the 'total noise budget' (NRC 2003) of SBNMS, the contributions and frequency characteristics of noise from biological, meteorological, and anthropogenic sources are being identified and mapped over various spatial and temporal scales. ARU data are being used to detect, localize and track vocalizing fish and whales (identified by the species-specific characteristics of their vocalizations) and calculate distributions and acoustic densities for different species in sanctuary waters throughout the year (Van Parijs et al. 2009, this Theme Section).

Acoustic signatures recorded on ARUs are also being linked to ships transiting the sanctuary using the Universal Shipborne Automatic Identification System (AIS). Under IMO's current mandates, all ocean-going commercial vessels $>300$ gross tons or carrying $>165$ passengers, as well as all tug boats/barges, are required to carry AIS transmitters (US Federal Register 2003, IALA 2004). The AIS is a VHF 'line of sight' transmitter that broadcasts a vessel's position, identity and various characteristics (including but not limited to length, beam, draught, cargo type, destination and speed) as often as every $2 \mathrm{~s}$. Through collaboration with the US Coast Guard, vessel tracking data from 4 AIS receivers allow SBNMS managers to track all vessels carrying AIS transmitters as they transit the sanctuary and beyond.

AIS tracks are used to identify the locations and times of each ship's closest point of approach (CPA) to an ARU, and empirical received sound levels at CPAs are used to estimate their source levels using the AIM (Frankel et al. 2003). AIM then estimates each ship's acoustic 'footprint' at each point in its AIS track. Fig. 1 shows AIM's estimate of the $100 \mathrm{~Hz} \frac{1}{3}$ octave bandwidth acoustic footprint, displayed using Matlab (The

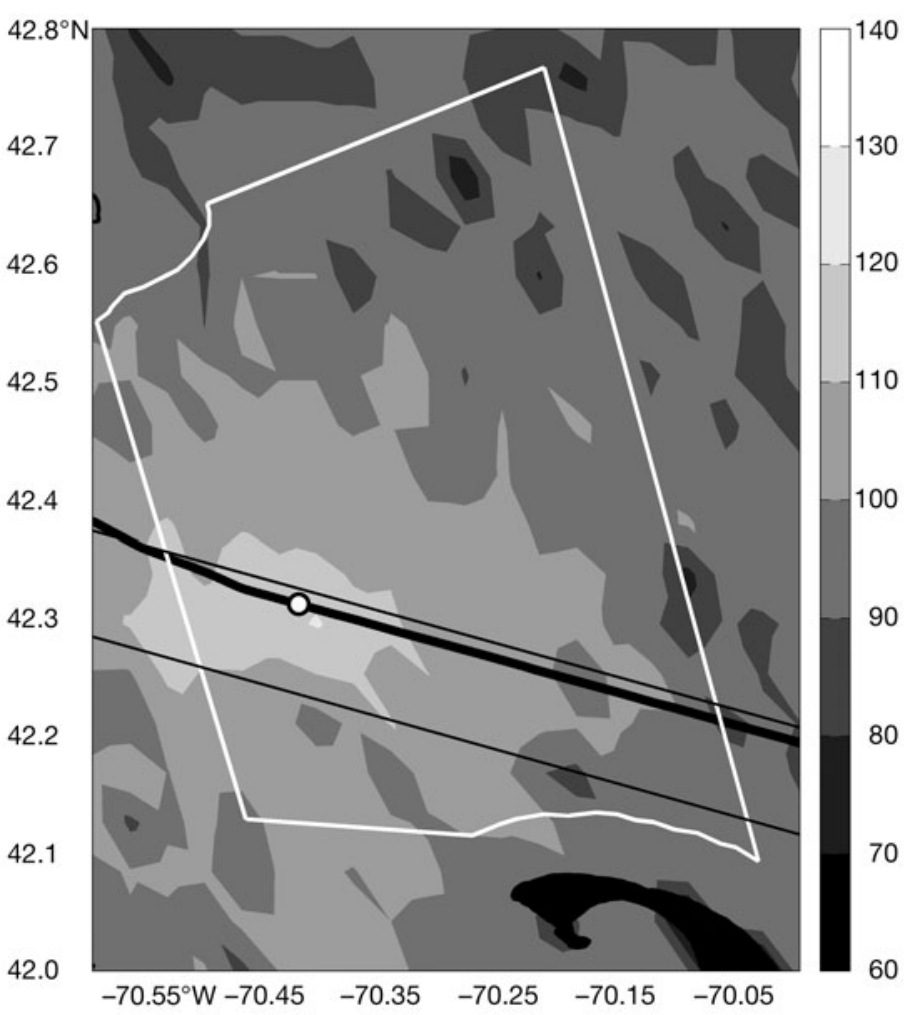

Fig. 1. Distribution of Acoustic Integration Model (AIM)-estimated received sound levels in the $100 \mathrm{~Hz}$ 1/3 octave bandwidth associated with a liquefied natural gas tanker transiting the Boston shipping lane on April 19, 2006. (O) Location of the tanker, (-) Automatic Identification System (AIS) track, (white line) boundaries of the Stellwagen Bank National Marine Sanctuary, and (-) Boston traffic separation scheme. Root-mean-squared received sound levels ( $\mathrm{dB}$ re $1 \mu \mathrm{Pa}$ ) are indicated by the scale on the right hand side 
Mathworks 2006), of a LNG tanker as it transited the SBNMS on April 19, 2006. Based on ARU received sound levels, the root-mean-square (RMS) source level for this vessel in the $100 \mathrm{~Hz} \frac{1}{3}$ octave band was estimated to be $175 \mathrm{~dB}$ referencing $1 \mu \mathrm{Pascal}$ ( $\mathrm{dB}$ re $1 \mu \mathrm{Pa}$ ). A recent study estimated the average $2 \mathrm{D}$ areas exposed by this ship to received levels $>120 \mathrm{~dB}$ and $160 \mathrm{~dB}$ re $1 \mu \mathrm{Pa}$ to be 240 and $1.1 \mathrm{n} \mathrm{miles}^{2}$, respectively (Hatch et al. 2008). These areas represent the zones in which received levels from continuous and impulsive (respectively) source types other than vessels in transit have been defined as harassing co-occurring marine mammals (NOAA 2005, 50 CFR 216).

Data from individual ARUs are also visualized as 'acoustic scenes' over user-selected time scales (i.e. years, seasons, months or days), using an open-source extensible sound analysis application called XBAT (Mills \& Figueroa 2005, Figueroa 2007) for developing sound analysis tools written in Matlab (The Mathworks 2006) and an XBAT plug-in called LTspec (Cortopassi 2007). Fig. 2 displays the $24 \mathrm{~h}$ distribution of low frequency sound recorded by an ARU placed in the shipping lane on the same day that the LNG tanker above transited the sanctuary. The peaks of low frequency sound appearing as black in the spectrogram (frequency over time, top panel) represent the close approaches of 3 transiting ships (the LNG tanker, an oil tanker and a cargo ship). The left and center panels (received levels over time) show that the majority of energy contained in these 3 acoustic events is distributed below $200 \mathrm{~Hz}$. The right panel depicts percentages of the day $(5,25,50,75$ and $95 \%)$ during which received levels across all sampled frequencies exceeded various intensity thresholds. As shown here for an ARU placed in the shipping lane, received levels at frequencies between 30 and $50 \mathrm{~Hz}$ were >82 dB $50 \%$ of the day and as high as $110 \mathrm{~dB} 5 \%$ of the day. A study based on data collected throughout 2006 indicated that noise generated by commercial shipping contributed significantly to noise levels in the sanctuary, with highly trafficked locations experiencing $2 \times$ the acoustic power of less trafficked locations for the majority of the time period analyzed (Hatch et al. 2008).

Current research in the SBNMS is focused on integrating information on the distribution and characteristics of human-induced noise (primarily from shipping), the distribution of primary production and prey species, physical oceanography and environmental conditions, the distribution of vocally active whales and fish species, and the behavioral ecology of individual whales (including feeding and acoustic behaviors). The goal of this research is to better understand the relationships among anthropogenic noise, animal behavior, and the survival and growth of individuals and populations. Software developed by Marine Acoustics and Cornell University's BRP is being used to integrate data from the AIS, ARUs, tags on whales, and environmental sensors to better understand the acoustic environment experienced by, as well as created by, vocally active animals in the sanctuary (Clark et al. 2009). Characterization of the status of SBNMS's underwater soundscape and its implications for the species that communicate and listen in the sanctuary (including humans) will inform the design of techniques to manage anthropogenic noise in the sanctuary.

For example, in 2006, the ONMS engaged in formal consultations with the US Coast Guard (USCG) and the US Maritime Administration (MARAD) under the NMSA (1992 as amended through 2000, Section 304(d)) regarding impacts, including acoustic impacts, associated with the proposed construction and operation of 2 offshore LNG import terminals $~ 1-3 \mathrm{n}$ miles from the western boundary of the SBNMS. Although located outside of sanctuary boundaries, these terminals were predicted to ensonify portions of the sanctuary at levels $>120 \mathrm{~dB}$ re $1 \mu \mathrm{Pa}$ on a weekly basis during their 25-40 yr span of use (USCG 2006a, b). This impact was prominent throughout interagency consultations regarding the terminals, and led to the inclusion of large-scale and long-term passive acoustic monitoring programs as operational criteria under their licenses (MARAD 2007a,b). Although this case provides precedent for considering the acoustic impacts within sanctuaries due to sources located outside sanctuary boundaries, resulting mitigation did not address noise from vessels associated with the terminals.

\section{Terrestrial}

Historical visitors to the Grand Canyon National Park (GCNP) were often awestruck by the silence as well as the scenery of the park: 'Besides the magnificent views of perpendicularly walled canyons and cliffs, I was most impressed with the profound silence - not a breath of wind today, not a sound, not a rustle of grass or weeds, not an insect murmur, not a falling rock. Silence absolute. Only my lifelong habit of hearing insects kept the sound in my imagination' (Sheldon 1912 in Carmony \& Brown 1993)

The GCNP provides an informative focus for discussions of noise management in terrestrial protected areas due to its extended history of noise management efforts and voluminous public documentation. Although noise impacts to nonhuman species have played a secondary role in this process, Grand Canyon's management history illustrates the challenges involved in protecting natural resources from noise. 


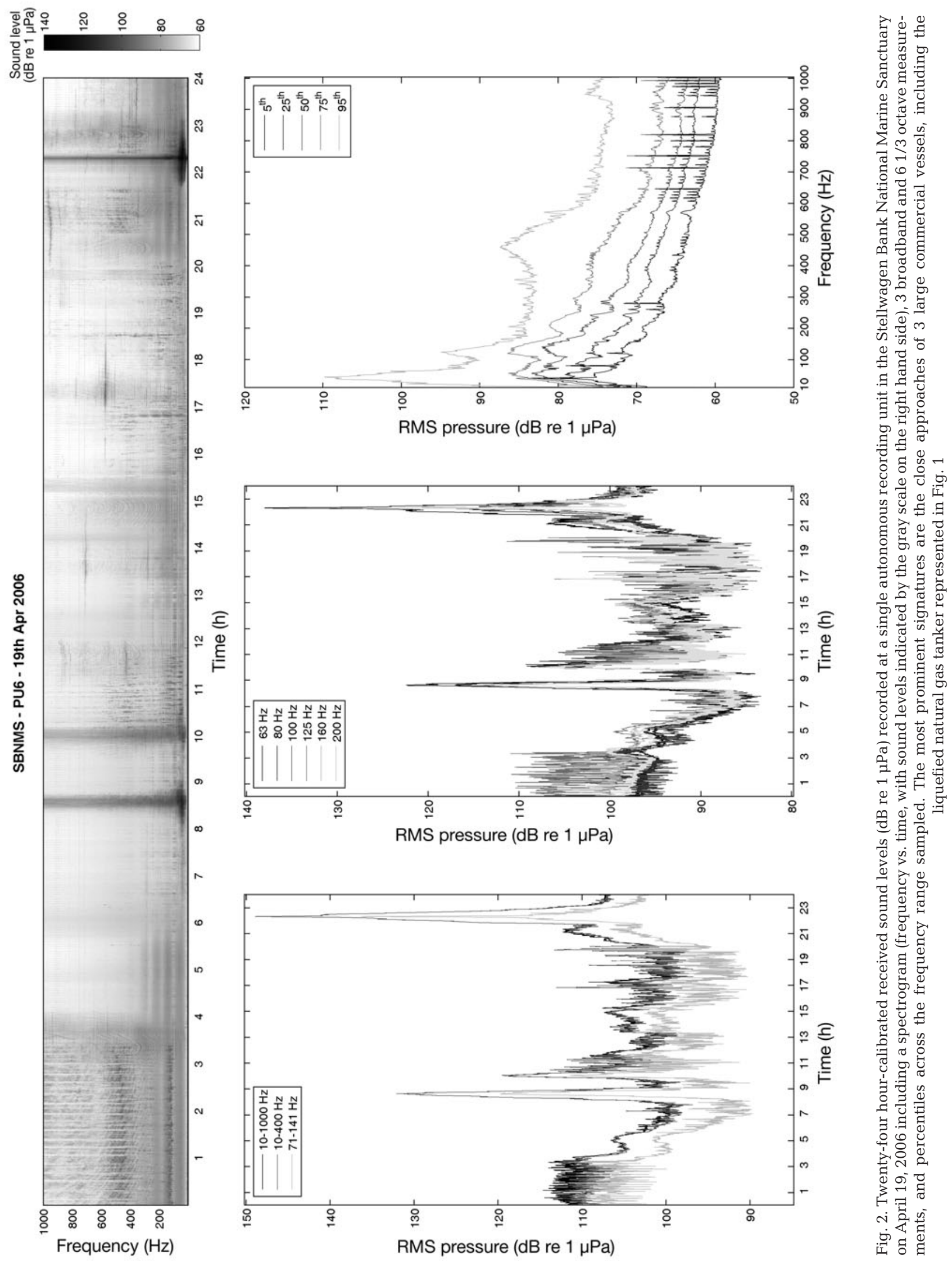


The GCNP is a globally significant natural area, attracting nearly 5 million visitors $\mathrm{yr}^{-1}$. Over $90 \%$ of the GCNP is proposed for wilderness status, and the NPS manages these areas as though they were so designated. The biota of the park includes many species of special concern, with 3 avian examples being the southwestern willow flycatcher, the Mexican spotted owl, and an introduced population of California condors. The quality of the acoustic environment has been explicitly recognized in federal legislation as an important feature of the park (US Grand Canyon National Park Enlargement Act, GCNPEA 1975). No place enjoys more substantial justification for rigorous and protective management from degradation due to noise.

Air tours have a long history at Grand Canyon. The first air tour overflight took place in 1919, which is the year that the GCNP was created (NPS 2008b). By the 1970s, there were tens of thousands of air tour flights at Grand Canyon per year. The US Congress explicitly recognized the burgeoning problem of air tour noise, specified natural quiet as a resource or value to be protected by the NPS, and requested studies on the impacts of overflights on the park (GCNPEA 1975). Motivation for an overflight management plan was dramatically elevated in 1986 when a collision between 2 air tour flights resulted in 25 fatalities.

The passage of the US National Parks Overflights Act (NPOA 1987) required a report from the NPS on the nature, scope, and effects of overflights in National Park units, including the degree to which 'natural quiet' had been restored to Grand Canyon. The report on the effects of aircraft overflights on the National Park System (NPS 1994) summarized >20 separate studies. It documented the extent of visitor interest in natural soundscapes, asserted that noise impacts begin at the threshold of human audibility, and provided a definition for the substantial restoration of natural quiet at Grand Canyon: '50\% or more of the park achieves natural quiet (no aircraft audible) for 75 to $100 \%$ of the day.'

This definition applied to noise from all aircraft, not just air tour aircraft. From a technical perspective, this definition has 2 potential gaps in its protective coverage. First, the definition ignores the received level of the noise source: aircraft noise that is barely audible is counted the same as aircraft noise that is deafening. Second, the definition places no limits on noise levels in just under $50 \%$ of the park area. Collectively, these gaps imply that substantial restoration of natural quiet could be achieved when slightly less than half of the park is exposed to unlimited amounts of noise, and the remainder is exposed to arbitrarily loud noise for just under $3 \mathrm{~h}$ (cumulative) during daylight hours. It is clear that simplicity was an important consideration to the authors of this definition, and it may have seemed unlikely that the idiosyncrasies of this simple definition would create today's management problems.

Progress towards an overflight plan for Grand Canyon has been hampered by disagreements between the NPS and the FAA, litigation, and a lengthy alternative dispute resolution process that failed to achieve a consensus management plan. A 2002 court decision found that the substantial restoration of natural quiet referred to noise from all aircraft, not just air tour aircraft (US Air Tour Association v Federal Aviation Administration 2002). High altitude jets are audible $>30 \%$ of the day at most sites in Grand Canyon. By the NPS definition, natural quiet cannot be substantially restored even if air tour activity were entirely eliminated. NPS 'clarified' its definition of substantial restoration of natural quiet in early 2008 in order to resolve this quandary. The clarified definition restricts the audibility criterion to aircraft flying below 18000 feet, with reductions in other aircraft noise to be pursued by a separate, unspecified process (US Federal Register 2008).

The Grand Canyon noise management process was initiated by the Grand Canyon and the NPS intermountain regional resource managers. The passage of the National Parks Air Tour Management Act (NPATMA 2000) induced the NPS to create a national program office in Fort Collins, Colorado, called the Natural Sounds Program. The overall mission of the program is to provide scientific and planning support to park units, and the office has explicit responsibilities to foster the development of air tour management plans (NPS 2008b). This office also sponsors a variety of research projects to broaden the scientific basis for assessing noise impacts to wildlife, visitor experience, and the integrity of park settings and resources.

Extensive acoustical monitoring at $>40$ sites in the GCNP confirms the results of extensive INM modeling: aircraft noise is audible throughout the park for $>30 \%$ of the daylight hours (Fig. 3). If a visitor does not want to hear aircraft at Grand Canyon, they need to be in a busy parking lot or near one of the rapids on the Colorado River. Monitoring efforts continue at Grand Canyon, with recent efforts focusing on noise levels under air tour corridors and in protected activity centers of Mexican spotted owls. The Natural Sounds Program is developing systems for indefinite deployment, to provide daily summaries of aircraft activity and track long-term trends in acoustical conditions. This parallels a broader NPS effort ('Vital Signs' monitoring) to transition from inventories of current conditions to collection of time series suitable for assessing trends and supporting adaptive management of natural and cultural resources. 


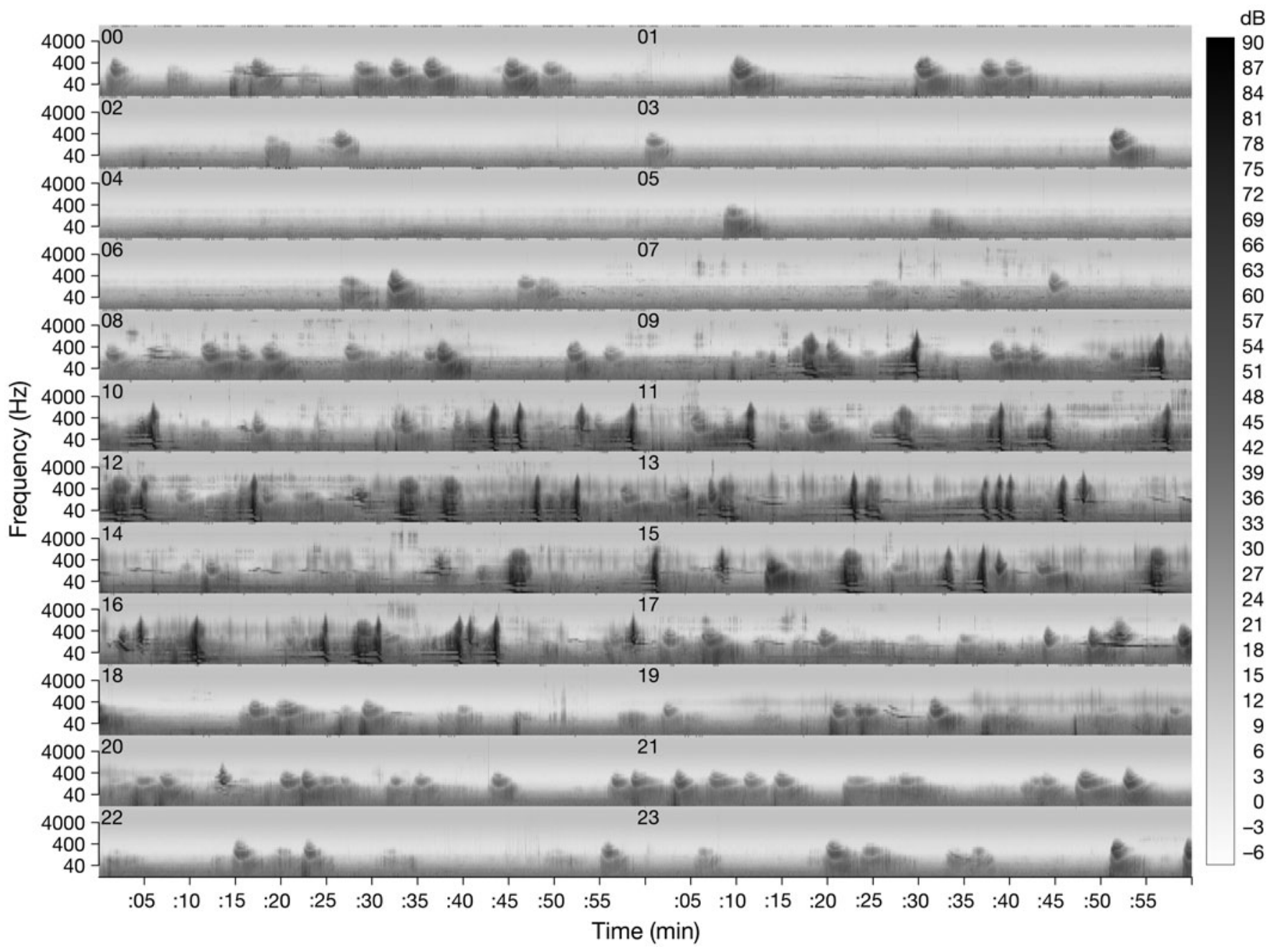

Fig. 3. A $24 \mathrm{~h}$ spectrogram of calibrated received sound levels ( $\mathrm{dB}$ re $20 \mu \mathrm{Pa}$, indicated in the scale bar) recorded at a single monitoring site in the Grand Canyon National Park on February 3, 2007, with $2 \mathrm{~h}$ of data presented in each row. Two types of aircraft noise events are numerous. High altitude commercial jet overflights are characterized by broadband signatures that are often $30 \mathrm{~dB}$ above background sound levels (e.g. 4 events between 01:00 and 02:00 h) with more abrupt beginnings than endings (jets radiate more noise aft than forward). Air tour helicopters are characterized by tonal signatures up to $50 \mathrm{~dB}$ above background (e.g. 3 prominent events between 09:00 and 10:00 h) with noticeable Doppler shifts at their closest points of approach

\section{DISCUSSION}

National parks and marine sanctuaries confront similar ecological and policy issues. Both seek to conserve natural resources that are portions of much larger ecosystems. Explicit noise management is not in effect for marine sanctuaries, but regulations are in place to manage noise in national parks. However, NPS regulations do not reference a consistent standard for protecting park resources and visitor experience. National parks and marine sanctuaries exclude or regulate most noisy commercial activities (i.e. oil and gas drilling, Department of Defense training activities).
Ambient noise in both parks and sanctuaries is largely generated by expanding transportation networks that extend far beyond their boundaries. Growth in transportation often requires increasing dispersion of traffic to relieve congestion and increase network capacity. Growth and dispersion mutually amplify the spread of noise across the globe. Although the current network of roads presents significant fragmentation and noise issues for wildlife and protected natural areas, expansion continues through local projects. Growth in air traffic and progress towards 'free flight' rules will spread noise more extensively on continental scales. Similarly, noise from maritime transportation is 
likely to be more broadly distributed in the future as previously inaccessible areas like the Arctic become accessible, and as the number and size of vessels increase.

Most transportation noise is concentrated at low frequencies, due to the characteristics of the sources and favorable conditions for long-distance propagation of longer wavelength signals. Marine environments have substantially lower sound absorption, leading to much larger footprints for each noise source. However, patterns of transportation noise exposure in parks and marine reserves are similar because the larger number and greater mobility of terrestrial noise sources compensate for the bigger footprints of marine noise sources.

A protected area's ecological integrity depends on the quantity and quality of time that key species spend within its boundaries, and the extent to which resource quality can be sustained or restored (Newmark 1987, Landry et al. 2001, Hooker \& Gerber 2004). Only $6 \%$ of marine protected areas (MPAs) containing cetacean habitat are $>10000 \mathrm{~km}^{2}$; this could thus be used to mitigate exposure of whales and dolphins to low frequency noise (Hoyt 2005, Agardy et al. 2007). A higher percentage of MPAs may afford protection for other species with smaller ranges. The addition of quiet buffer areas around existing protected areas has been suggested to protect highly vagile species (Haren 2007, Hatch et al. 2008). Quiet zones can be implemented by expanding recommended exclusion areas (i.e. through consultations under the NMSA) to provide adequate distance for the noise to attenuate. Buffers for louder and lower frequency source types must be wider to achieve the same level of protection.

Although many protected areas encompass fragments of ecosystems, they still offer 2 opportunities to achieve healthier ecological function. If conditions inside reserves are substantially improved relative to conditions elsewhere, then reserves could provide opportunities to document and quantify some of the benefits of more spatially extensive protection. Additionally, restoring acoustical integrity inside protected areas will result in lowered noise levels in adjacent habitats, even in the absence of buffer zones. Natural quiet does not propagate like noise, but the benefits of noise management extend beyond park and sanctuary boundaries.

Threatened and endangered species can be viewed as serving the same purpose in wildlife conservation that parks and sanctuaries serve for complete ecosystems: they provide foci for management actions, which may convey additional benefits to other species. Consultations with the NOAA and the US Fish and Wildlife Service under Section 7 of the ESA are routinely used to evaluate the effects of noise from proposed federal actions on listed species and their critical habitats. These consultations play a significant role in federal actions with limited scopes, but have not been prominent in broader actions like regional airspace redesign or ship routing measures. Although a few programmatic-level federal actions could subject sectors of traffic to evaluation under the ESA, most consultations could not address noise produced by the majority of traffic. Provisions within the ESA and the MMPA empower the US Secretaries of Interior and Commerce to issue protective regulations (i.e. ESA Sections $4 \mathrm{~d}$ and 11f and MMPA Section 103a-f) and enforce prohibitions against injury or harassment (i.e. ESA Section 9a or MMPA Section 107a). These could be invoked to address acoustical impacts from general classes of activities or noise sources. However, applications of the ESA and the MMPA remain subject to the limits of their scopes and jurisdictions, the most important of which being their strong emphasis on individual species and associated critical habitats.

Although marine mammals and species covered by the ESA can serve as salient indicators of conditions affecting the local fauna, disproportionate focus on a few species may generate unbalanced assessments of potential impacts and create specialized management plans that do not ensure sustainable ecosystem function. This biological common sense is echoed in legislative language, which mandate both retaining populations as 'a significant functioning element in the ecosystem of which they are a part' (MMPA 1972 as amended through 2007) and providing 'a means whereby the ecosystems upon which endangered species and threatened species depend may be conserved' (ESA 1973 as amended through 2004). The biological necessity of preserving sustainable habitats points to an ecosystem approach to management, as does the regional scope of the transportation networks that generate noise. Managing noise to standards based on species of special concern creates the potential to place scientifically or economically unjustifiable emphasis on those species and the noise sources that affect them, while ignoring other noises and species that must be managed to achieve environmentally sustainable results.

Many debates regarding noise regulation focused on the acute and immediate effects of intense noise exposures: hearing loss, injury, and death. These debates often center on the fates of individuals rather than populations, because physical constraints limit these effects to relatively short ranges. Excessive focus on dramatic consequences has the same costs as excessive focus on endangered species: misplaced emphasis and neglect of environmental factors that may be crucial for sustainable conservation outcomes. 
Chronic elevation of ambient sound levels is pervasive in marine and terrestrial environments. The contributions of any single source are often subtle, and the sources are spatially and temporally diffuse. In aggregate, they impose unremitting impediments to acoustical communication and degrade auditory awareness. Numerous studies have documented the effects of noise on communication, and compromised awareness of the incidental sounds of nature may pose more serious threats. A calling animal can adapt to noise by calling louder, repeating its message, shifting its calling activity to a quieter period, or changing its signal. However, abiotic sounds and incidental sounds produced by animals (locomotion, respiration) cannot adapt; the range of detection just shrinks. Awareness of abiotic and incidental sounds is important, as the ability to hear evolved before the emergence of intentional acoustical communication (Fay \& Popper 2000).

The costs of lost auditory awareness have not been adequately analyzed, perhaps because plausible metrics and functional interpretations have not been established. Good metrics will be capable of documenting the full range of anticipated conditions while providing adequate spatial and temporal resolution to address ecological and resource management priorities. Good metrics will also relate directly to functional consequences for organisms, and be readily interpreted by resource managers and public stakeholders. However, excessive emphasis on simplicity can produce metrics that have unintended idiosyncrasies, as illustrated by the Grand Canyon narrative.

The impacts of lost acoustical awareness are challenging to quantify. The range of sounds produced by an organism can be quantified through acoustical monitoring, but the range of sounds heard and the degree of resistance to masking require specialized studies in laboratory settings. Research has documented major differences among marine mammal auditory systems (see Wartzok \& Ketten 1999). The vocal ranges of many species provide only a rough indication of their hearing capabilities (reviewed by Southall et al. 2007). For example, Mann et al. (1997) showed that the American shad Alosa sapidissima, which was previously thought to detect only low-frequencies, can also detect ultrasonic sounds like those produced by toothed whales.

In addition to substantial scientific challenges, new quantitative frameworks for analyzing noise impacts confront institutional challenges. The development of regional, ecosystem approaches to managing both terrestrial and marine transportation noise must evolve from the joint efforts of several federal agencies. Transportation networks are managed by one set of federal agencies; natural and cultural resources are managed by another. Cooperative management is impeded by differences in agency missions, professional cultures, and historical precedents. Preserving living natural resources represents a core priority for park and sanctuary managers, but it is an inconvenient constraint for transportation planners. The challenge of bridging different agency cultures is compounded by inertial processes within each agency (Owen 2003, US Government Accountability Office 2006a,b, US Department of Commerce Office of Inspector General 2008).

Concerns about new precedents, defending past practices, and preserving established routines, even within resource management agencies, present formidable impediments to innovation. If prior NEPA documents met procedural requirements, any novelty may be perceived as an unnecessary risk. The desire to develop standards for consistent environmental analyses is in some respects antithetical to ongoing exploration. Furthermore, the cost of integrating new metrics into decision support tools may be high, and the broader user community may not welcome increasing complexity in tools that they use routinely.

Humans share the terrestrial environment with wildlife in National Parks. Terrestrial noise management is informed and encumbered by the history of community noise management. Historical noise studies and regulations focused on maximum tolerable conditions for humans, in terms of health effects or annoyance. The concept of preserving a high quality acoustic environment has been largely ignored until very recently. The US NPS Organic Act (1916) demands that the NPS preserve natural and cultural resources unimpaired for future generations, and the 2006 Management Policies (NPS 2006) provide explicit guidance for managing acoustic environments to meet this high standard. An enormous gulf separates the outstanding acoustical conditions that the NPS is required to protect and the noise exposures that result in health effects or high levels of annoyance. Established metrics and standards have limited relevance to park settings. Therefore, ongoing efforts to preserve and restore the quality of acoustic environments in protected natural areas require both scientific innovation and institutional processes that encourage federal partners to support new noise management practices.

Restoration of acoustic environments demands appropriate reference conditions. The NPS identifies the natural acoustical conditions that prevailed in the absence of today's noise exposure as the reference. This requires the development of rigorous procedures for measuring the contributions of noise and removing them from current monitoring data. Analyses of historical patterns of noise exposure can also provide useful information. In marine environments, comparisons of recent data with recordings from the mid 20th century have documented significant trends (Andrew et al. 
2002, McDonald et al. 2006, Andrew et al. in press). Intensive case studies, like the one taking place in Stellwagen Bank National Marine Sanctuary, also provide opportunities to parse sound level budgets into the contributions of many sources.

In the marine realm, emerging noise management practices are not burdened by the history of community noise management. The NMSA provides broad statutory authority to protect and manage sanctuary resources. The ONMS recently identified noise as a threat to sanctuary resources, signifying increased programmatic awareness of the issue. Substantial questions remain: What role will noise assessments play in overall resource management? How will the desired acoustical conditions in sanctuaries be identified and specified? The broad mandate of the NMSA provides a unique opportunity to create noise management practices and regulations that represent today's best available science.

Marine sanctuaries, however, confront significant obstacles to public education and outreach on noise issues. Access limits the number of visitors to sanctuaries: an estimated 12.4 million people $\mathrm{yr}^{-1}$ visit US national marine sanctuaries (ONMS unpubl. data). Sanctuary visitors remain largely isolated from the underwater acoustic environment. Although 10 000 to 20000 people $\mathrm{yr}^{-1}$ dive in sanctuary waters (ONMS unpubl. data), many never enter the water and human ears are not adapted to underwater hearing. Many features of marine mammal hearing and auditory awareness may have no analogs in human experience.

In contrast, the NPS hosts 275 million visitors $\mathrm{yr}^{-1}$ (NPS 2007), and humans are better able to detect low frequency noise than many wildlife species in parks (Dooling \& Popper 2007). Numerous surveys of park visitors and the American public confirm that a large proportion of the public regards opportunities to experience the sounds of nature as important reasons for establishing and visiting national parks (McDonald et al. 1995, Haas \& Wakefield 1998, Mace et al. 1999, Mace et al. 2004). Measures that provide park visitors with outstanding opportunities to experience natural acoustic environments will be protective for wildlife.

This paper has focused on 2 substantive reasons to manage human-induced noise in natural areas. The first reason - to minimize or mitigate impacts to humans and wildlife-has thus far been the most prominent reason invoked for noise control. The second reason - to enhance visitor experiences by preserving visitor listening opportunities and creating conditions to observe undisturbed wildlife — has a long history within US national parks but remains a placeholder in national marine sanctuaries. Noise also degrades the performance of environmental monitor- ing technologies. Passive acoustical monitoring is one of the least invasive ways to document the distribution and behavior of animals (see Van Parijs et al. 2009). The range over which passive acoustical tools can detect, locate and track individuals is constrained by background noise in the frequencies of interest. This justification for quieting is receiving increased attention in fishery research (NOAA 2007b). Noise also interferes with the use of active acoustics in underwater environments for a variety of scientific, commercial, and defense applications. Amplifying the transmitted signal is one method of compensating for increased noise, but this will exacerbate environmental concerns about the effects of the sound broadcasts. These user groups could plausibly engage with other stakeholders to help quiet the ocean environment.

\section{How to proceed}

Despite differences in physical environmental and historical contexts, protected areas on land and in the ocean confront the same challenge to develop and implement noise management policy in spite of scientific, organizational and political uncertainty. The case studies presented here illustrate common problems faced by natural resource managers, and their mutual interests require more substantial interaction and collaboration. Four parcels of common ground emerge from these case studies that would provide a basis for more rigorous and effective management of noise in protected natural areas.

(1) Investing in monitoring programs and data management. A systematic inventory of acoustical conditions in protected natural areas is the crucial first step towards documenting the extent of current noise exposure, and estimating the pristine historical or desired future conditions for the resources. The essence of sound is pressure fluctuations, and acoustic environments are dynamic. Inventories should account for diel and seasonal patterns in both natural sources and noise, as well as the range of variation attributable to other factors (weather, faunal composition, population densities). Investment in monitoring program design will ensure that subsequent investments in capacity and infrastructure meet system-wide objectives efficiently and effectively.

The first systematic efforts to monitor sound levels in national parks began in the late 1980s, and some data are available for $>50$ park units, or $\sim 13 \%$ of units in the National Park System. In contrast, passive acoustic monitoring programs in national marine sanctuaries to date have not been designed to support system-wide analyses (Hatch et al. 2008, McKenna et al. 2008, C. W. Clark \& D. Croll unpubl.). Acoustical monitoring proto- 
cols and methods for statistically summarizing these data should be identified for the National Marine Sanctuary System. System-wide standardized monitoring will help sanctuary managers establish priorities both at site and system levels by evaluating which sanctuaries contain relatively quiet versus relatively noisy conditions, and assessing both contemporary and historical (where data are available) trends within and among sites. Sampling plans should be informed by modeling that addresses temporal and/or spatial variability in bathymetry, oceanographic conditions (e.g. wind, wave, salinity and temperature), bottom types, marine animal distributions, and human activity patterns.

Acoustical monitoring data must be organized, available, and readily interpreted in order to be useful to resource managers. Data management strategies should be developed for monitoring systems in both parks and sanctuaries. Quality control practices must be established to ensure the integrity of monitoring data and the associated metadata. Data servers should provide flexible interfaces for extracting information from relational databases spanning all the available data from sanctuaries or parks. The NPS is developing a central archive of all acoustical data collected in park units. It is also implementing standardized file formats for sound pressure data, and a metadata framework that supports flexible information retrieval. These data will be transitioned into the NPS DataStore for integration with other natural resource monitoring information.

Well-maintained data management capabilities are central to adaptive management. Passive acoustical data collected to fulfill all resource agency permit and consultation requirements should be centralized and accessible so that they can inform subsequent management decisions. These recommendations echo comprehensive priorities for ocean science in the US for the next decade, which are included in a recent executive report (US Joint Subcommittee on Ocean Science and Technology, JSOST 2007).

(2) Expanding the resolution and scope of impact assessment tools. Accumulating acoustical monitoring data will be of very limited value without efficient and informative tools for rendering and summarizing the information. Monitoring data have been rendered as long-term spectrograms (see Figs. $2 \& 3$ ), which provide an immediate opportunity to qualitatively assess the number and variety of sound sources, and the degree of noise pollution. However, quantitative comparisons among seasons and across different sites will require extraction of meaningful statistical summaries of these sound data. These summaries, or acoustical metrics, are also essential for resource management plans.
Many qualities of good metrics have emerged from recent experience. They must be routine to extract from acoustical data, and be readily implemented for inclusion in the output of acoustical models. They should relate directly to functional consequences for organisms. The metrics may involve complex calculations, but the associated consequences should be straightforward to interpret for resource managers and the interested public. Some functional consequences can be identified as important for most organisms: degradation of acoustical awareness, compromised acoustical communication, disturbance of important behaviors (reproduction, foraging, territorial defense, resting), and physiological allostasis. Emphasis on functionally significant metrics is beneficial in that noise impact assessments can be more readily integrated with costs attributed to other environmental stressors. This integration should consider both cumulative and possible synergistic impacts among stressors (Darling \& Côté 2008).

To support the development of these metrics, resource management agencies should stimulate several areas of research. Additional comparative research into wildlife hearing is needed to provide better frameworks for quantifying the effects of noise masking and their functional costs. Of special interest are ecological or systematic affinities among species that may offer a reliable basis for inferring similar hearing capabilities. In marine systems, phylogenetic and estimated functional hearing differences have been used to identify appropriate animal models for species whose hearing has not been studied (Southall et al. 2007). Studies of hearing performance in freeranging animals could complement laboratory studies documenting the extent to which attention and information processing constraints introduce additional noise penalties beyond psychophysical masking. Studies of wildlife behavior, spatial distribution, and demographic parameters should be pursued wherever conditions are favorable for investigating their relationships to noise. Special attention should be given to eliminating or minimizing potential confounding factors (see Habib et al.'s 2007 study of ovenbird breeding in relation to chronic noise). Results from marine and terrestrial systems that can inform the design of new metrics should be shared to enhance standardization among impact assessment frameworks.

Acoustical modeling provides (1) an important tool for environmental impact analyses; (2) a rigorous framework for spatial interpolation, when acoustical monitoring data are sparsely distributed; (3) opportunities to predict spatial correlation patterns, variations in exposure, and the degree to which different metrics help identify and document these patterns; and (4) 
direct capacity to investigate the impacts of possible future activities, and to compare the effects of a range of alternative scenarios. Acoustical modeling is currently used to assess the potential effects of noise from all major terrestrial transportation projects in the US (e.g. airport and highway construction), and some marine transportation projects (e.g. port or dock construction). Modeling should be used to assess noise impacts associated with all major marine transportation projects, including federal actions that may change the distribution, density, speed or composition of vessel traffic within and among coastal areas.

Acoustical models and statistical techniques should be used to characterize uncertainty in noise management. Estimates of statistical power and error associated with both monitoring data and model results provide important information to managers tasked with applying scientific information for resource conservation. By using modeling and statistics to evaluate the impacts of missing data or missing variables, managers can identify targets for future research, design mitigation based on precautionary pragmatism, and update plans as the quality of information improves.

In the face of considerable scientific uncertainty, the precautionary principle should be applied to ensure that areas of designated national importance fulfill their protective mandates. Particular care should be used in interpreting negative results. Studies that fail to detect a specific form of response should not be immediately interpreted as evidence for harmless habituation or acclimation to high ambient noise environments.

(3) Enhancing coordination and the governance structure for managing noise in protected areas. Interagency coordination among scientists and resource managers concerned with noise impacts to wildlife in natural protected areas should be strengthened. Increased communication among federal agencies engaged in noise impact assessment would enhance compliance with the US National Technology Transfer and Advancement Act (NTTAA 1995). As clarified by the White House Office of Management and Budget (OMB), the NTTAA promotes the use of consensus-based standards rather than agency-specific standards whenever possible and/or appropriate (OMB 1998).

The US Ocean Action Plan (2004) responded to the US Commission on Ocean Policy's recommendations by creating a new executive-level interagency coordinating and governance structure - the JSOST. Reporting to the new Interagency Committee on Ocean Science and Resource Management Integration, the JSOST convened an Interagency Task Force on Anthropogenic Sound and the Marine Environment. This task force was created to address an acknowl- edged need for increased communication and collaboration across the federal agencies most directly involved in underwater noise impact assessment. A similar task force could provide a forum for future dialog regarding the role of marine protected areas in US ocean noise policy. Such interagency information sharing to enhance research, analysis, and exploration within US marine protected areas was a central intent of US Presidential Executive Order 13158 (2000), which could also be facilitated by the Marine Protected Areas Federal Advisory Committee.

Existing scientific or technical fora such as the Accredited Standards Committees addressing Bioacoustics and Noise (operating under the American National Standards Institute), and meetings of the Acoustical Society of America, should be attended by wildlife noise specialists from the NPS and the ONMS to promote information sharing. Key national (i.e. George Wright Society Biennial Conference on Parks, Protected Areas, and Cultural Sites) and international (i.e. International Marine Protected Areas Congress) fora should also be further developed to ensure interdisciplinary communication among resource management professionals.

The final reports of the US Commission on Ocean Policy (2004) and the Pew Oceans Commission (2003) recommended advancing regional approaches to ecosystem-based management. Noise should be addressed by emerging regional management frameworks (i.e. The Gulf of Mexico Program, West Coast Governors' Agreement on Ocean Health, Northeast Regional Ocean Council), and during the design, implementation and evaluation of protected areas. Parks and sanctuaries should be afforded heightened levels of noise protection. Sanctuaries should become quiet refugia for species, as well as enhanced environments for the development of science and technology that promote the research and management objectives throughout the regions they occupy.

The scale of low frequency transportation noise demands international US engagement to promote quieting technologies and operating conditions. Large commercial shipping traffic is managed by the IMO. As an active importing nation that does not build, own or operate many of its commercial ships, the US generally asserts its policy regarding environmental best practices for these vessels through port access control and through multi-lateral cooperation, agreements and conventions. Thus, action at the IMO level will be central to any initiative to effectively control shipping noise in US waters and internationally. Fortunately, a US proposal to the IMO to create a correspondence group charged with developing guidelines for quieting commercial ships was recently ratified (IMO 2008). Technical solutions that will inform and draw upon 
regional initiatives and monitoring programs will be explored in this forum. Commercial jet aircraft are substantially quieter today than 4 decades ago. The National Aeronautics and Space Administration (NASA) and the FAA have active research programs that pursue further advances in aircraft quieting (GAO 2008).

(4) Engaging and educating US citizens regarding the benefits of quieting natural areas. The levels of protection enjoyed by wildlife in US protected areas are driven by the stated or represented values of American voters. Sanctuaries and parks represent unique educational contexts in which visitors and users could offer opportunities for place-based engagement and outreach. In addition, advances in multi-media could provide increasing opportunities to expose a broad audience to the resources and settings of protected natural areas. These forms of outreach are particularly important for marine sanctuaries, which are less accessible. Wildlife noise specialists should collaborate with communication specialists to teach people about the importance of quiet natural environments. These collaborations should prioritize the development of new visualization techniques to allow people to see changes in soundscapes over time scales, and spectral bandwidths outside of their direct experience.

Although specific issues regarding impacts due to noise (e.g. those of sonar on whales) have been highly publicized, this type of public dialog has generated more alarm than enlightenment. Frequent litigation generates an adversarial climate, which inhibits constructive engagement of stakeholders in a collaborative search for balanced and sustainable resolutions. Public discussions of noise management for protected natural and cultural areas must emphasize the clear distinction between incidental and purposeful production of sound. This distinction will encourage all stakeholders to engage proactively in the control of needless noise to increase both the efficiency and the capacity of purposeful acoustic transmissions.

\section{CONCLUSION}

US national marine sanctuaries and national parks represent opportunities for interagency collaboration in developing management guidelines for noise within marine and terrestrial natural protected areas. Humaninduced noise has recently been identified as a threat to sanctuary resources (NOAA 2007a), and efforts to manage noise in national parks has a longer history. Despite differences in context, challenges faced by managers addressing noise in parks and in sanctuaries are similar and would benefit from being addressed conjointly.

Noise pollution is proliferating, and many communities (including New York City) are increasingly focused on solutions. A collective refocusing of noise impact evaluation towards functional costs to resources and visitors will protect wildlife more effectively and enhance public appreciation of the quality of all acoustic environments. The value of positive aural experience is demonstrated by the sale of natural sound recordings (e.g. Skeoch 2008), and the construction of 'soundscapes' (Schafer 1993) in private residences (Blesser \& Salter 2006) and public spaces (Bandt \& Paine 2001, Gutman 2007). It is ironic that the popularity and uses for natural sound recordings are expanding during an era when opportunities to enjoy these auditory experiences in nature are contracting rapidly. We modify our interior spaces to mimic acoustical conditions that we are failing to protect in our parks and sanctuaries.

It follows that management to actualize outstanding acoustical conditions cannot proceed by accepting today's degraded conditions as the baseline for ongoing environmental impact analyses. The quietest marine and terrestrial environments must be vigorously protected, as they are the most vulnerable to noise intrusions. Exceptional environments for hearing natural sounds are also exceptional for detecting noise. Very little noise energy is required to substantially degrade listening conditions when the natural sound levels are very low. Like other crucial and endangered resources, quiet merits the highest standards for preservation and restoration.

Acknowledgements. We thank D. Ponirakis, A. Frankel and M. Thompson for assistance with creating SBNMS figures for this study. K. McMullen, S. Falzarano and L. Levy provided acoustical data from the GCNP. We also thank 4 anonymous reviewers for suggestions that improved the paper.

\section{LITERATURE CITED}

Agardy T, Aguilar N, Cañadas A, Engel M and others (2007) A global scientific workshop on spatio-temporal management of noise. Report of the Scientific Workshop Puerto Calero, Lanzarote June 4-6, Dokumente des Meeres $\mathrm{GmbH}$, Darmstadt

Aidala FE, Keenan RE, Weinberg H (1998) Modeling high frequency system performing in shallow-water rangedependent environments with the comprehensive acoustic simulation system (CASS). Tech Dig, NUWC Division, Newport, RI, p 54-61

Andrew RK, Howe BM, Mercer JA (2002) Ocean ambient sound: comparing the 1960s with the 1990s for a receiver off the California coast. Acoustics Res Lett Online 3:65-70

Andrew RK, Howe BM, Mercer JA (in press) Long-term trends in low-frequency ambient noise for four sites off the North American west coast. J Acoust Soc Am 
Babisch W (2006) Transportation noise and cardiovascular risk: review and synthesis of epidemiological studies, dose-effect curve and risk estimation. WaBoLu-Hefte 01/06, Umweltbundesamt, Berlin. www.umweltdaten.de/ publikationen/fpdf-1/2997.pdf (accessed 15 May 2008)

Bandt R, Paine G (2001) Cairns International Airport sound experience (1996 -). The Australian sound design project: a database and website for a more considered acoustic environment, University of Western Sydney. www.sounddesign.unimelb.edu.au/web/biogs/P000264b.htm (accessed 15 May 2008)

Blesser B, Salter L (2006) Spaces speak, are you listening? Experiencing aural architecture. MIT Press, Cambridge, MA

Carmony NB, Brown DE (eds) (1993) The wilderness of the southwest: Charles Sheldon's quest for desert bighorn sheep and adventures with the Havasupai and Seri Indians. University of Utah Press, Salt Lake City, p 11

CEQ (US Council on Environmental Quality) (1987) Regulations for implementing the procedural provisions of the National Environmental Policy Act (40 CFR 1500 - 1508)

CEQ (1997) Considering cumulative effects under the National Environmental Policy Act. Council on Environmental Quality, Executive Office of the President, Washington, DC. January.

Chandler WJ, Gillelan H (2004) The history and evolution of the National Marine Sanctuary Act. Environ Law Reporter News Anal 34:10505-10565

CIE (Center for Independent Experts) (2006) CIE summary report: review of AIM. Independent system for peer review. University of Miami, Washington, DC

Clark CW, Ellison WT, Southall BL, Hatch L, Van Parijs SM, Frankel A, Ponirakis D (2009) Acoustic masking in marine ecosystems: intuitions, analysis, and implication. Mar Ecol Prog Ser 395:201-222

Cortopassi K (2007) LTspec tool. Cornell University Bioacoustics Research Program, Ithaca, NY

Côté SD (1996) Mountain goat responses to helicopter disturbance. Wildl Soc Bull 24:681-685

Darling ES, Côté IM (2008) Quantifying the evidence for ecological synergies. Ecol Lett 11:1278-1286

Dolman SJ (2007) Spatio-temporal restrictions as best practice precautionary response to ocean noise. J Int Wildl Law Policy 10:219-224

Dooling RJ, Popper AN (2007) The effects of highway noise on birds. Report to the California Department of Transportation, Division of Environmental Analysis. www.dot.ca.gov/ hq/env/bio/files/caltrans_birds_10-7-2007b.pdf (accessed 02 December 2008)

Encyclopædia Britannica (2008) Encyclopædia Britannica online. www.britannica.com (accessed 15 May 2008)

EPA (US Environmental Protection Agency) (1999) Consideration of cumulative impacts in EPA review of NEPA documents. Office of Federal Activities (2252A) EPA 315-R99-002/May 1999. www.epa.gov/compliance/resources/ policies/nepa/cumulative.pdf (accessed 02 December 2008)

ESA (US Endangered Species Act) (1973 as amended through 2004) 7 USC 136, 16 USC 460 et seq

FAA (US Federal Aviation Administration) (2006) Environmental Impacts Order 1050.1E, CHG1. http://rgl.faa.gov/ regulatory_and_guidance_library/rgorders.nsf/0/2bb5c387 6ba31261862571810047a403/\$FILE/Order1050.1ECHG1. pdf (accessed 05 March 2009)

FAA (2008) Administrator's fact book. www.faa.gov/about/ office_org/headquarters_offices/aba/admin_factbook/media/ January_2008_Fact_Book.pdf (accessed 02 June 2008)

Fay RR, Popper AN (2000) Evolution of hearing in vertebrates: the inner ears and processing. Hear Res 149:1-10

Fidell S (2003) The Shultz curve 25 years later: a research perspective. J Acoust Soc Am 114:3007-3015

Figueroa H (2007) XBAT v5. Cornell University Bioacoustics Research Program, Ithaca, NY. http://xbat.org/ (accessed 15 May 2008)

Fleming GG, Plotkin KJ, Roof CJ, Ikelheimer BJ, Senzig DA (2005) Assessment of tools for modeling aircraft. Federal Interagency Committee on Aircraft Noise (FICAN). www.fican.org/pdf/Assessment_ToolsModeling_NPS.pdf (accessed 02 June 2008)

Frankel AS, Ellison WT, Buchanan J (2002) Application of the Acoustic Integration Model (AIM) to predict and minimize environmental impacts. Oceans '02 MTS/IEEE 3: 1438-1443

Frid A (2003) Dall's sheep responses to overflights by helicopter and fixed-wing aircraft. Biol Conserv 110:387-399

GAO (US Government Accountability Office) (2006a) National Parks Air Tour Management Act: more flexibility and better enforcement needed. GAO-06-263

GAO (2006b) National parks air tour fees: effective verification and enforcement are needed to improve compliance. GAO-06-468

GAO (2008). FAA's and NASA's research and development plans for noise reduction are aligned but the prospects of achieving noise reduction goals are uncertain. GAO-08384

GCNPEA (US Grand Canyon National Park Enlargement Act) (1975). Pub L 93-620

Grumbine RE (1994) What is ecosystem management? Conserv Biol 8:27-38

Gutman GM (2007) Creating a healthy environment for older populations. In: Robinson M (ed) Global health and global aging. Josey-Bass, New York, pp 281-291

Haas GE, Wakefield TJ (1998) National Parks and the American public: a national public opinion survey on the National Park System. National Parks Conservation Association, Washington, DC

> Habib L, Bayne E, Boutin S (2007) Chronic industrial noise affects pairing success and age structure of ovenbirds Seiurus aurocapilla. J Appl Ecol 44:176-184

Halpern BS, Walbridge S, Selkoe KA, Kappel CV and others (2008) A global map of human impact on marine ecosystems. Science 319:948-952

Haralabidis AS, Dimakopoulou K, Vigna-Taglianti F, Giampaolo M and others (2008) Acute effects of nighttime noise exposure on blood pressure in populations living near airports. Eur Heart J 29:658-664

Haren AM (2007) Reducing noise pollution from commercial shipping in the Channel Islands National Marine Sanctuary: a case study in marine protected area management of underwater noise. J Int Wildl Law Policy 10: 153-173

Hatch L, Clark C, Merrick R, Van Parijs S and others (2008) Characterizing the relative contributions of large vessels to total ocean noise fields: a case study using the Gerry E. Studds Stellwagen Bank National Marine Sanctuary. Environ Manage 42:735-752

Hester KC, Peltzer ET, Kirkwood WJ, Brewer PG (2008) Unanticipated consequences of ocean acidification: a noiser ocean. Geophys Res Lett 35:L19601

Holger DK (ed) (2003) Special issue on noise policy in America. Noise Control Eng J 51: 117-184

> Hooker SK, Gerber LR (2004) Marine reserves as a tool for ecosystem-based management: the potential importance of megafauna. Bioscience 54:27-39

Hoyt E (2005) Marine protected areas for whales, dolphins 
and porpoises. Earthscan, London

IALA (International Association of Marine Aids to Navigation and Lighthouse Authorities) (2004) IALA guideline no. 1028 on the Automatic Identification System (AIS). I. Operational issues, edn 1.3. Saint Germain en Laye, France

IMO (United Nations' International Maritime Organization) (2008) Minimizing the introduction of incidental noise from commercial shipping operations into the marine environment to reduce potential adverse impacts on marine life. Mar Environ Prot Comm 58:25

Jette SD, Cembrola JM, Mitchell GH, Fetherston TN II (2005) Marine mammal acoustic effect modeling conducted for the Undersea Warfare Training Range preferred site at Onslow Bay. NUWC-NPT Technical Report 11712, Naval Undersea Warfare Center, Division Newport, RI

JSOST (Joint US Subcommittee on Ocean Science and Technology) (2007) Charting the course for ocean science in the United States for the next decade: an ocean research priorities plan and implementation strategy. National Science and Technology Council, Office of Science and Technology Policy, Council on Environmental Quality, Executive Office of the President. http://ocean.ceq.gov/ about/sup_jsost_prioritiesplan.html (accessed 02 December 2008)

Keenan RE (2000) An introduction to GRAB eigenrays and CASS reverberation and signal excess. Oceans 2000 MTS/IEEE 2:1065-1070

Landry M, Thomas VG, Nudds TD (2001) Sizes of Canadian national parks and the viability of large mammal populations: policy implications. George Wright Forum 18:13-23

Lazauski CJ, Mitchell GH, Fetherston TN II (1999). Method for determining acoustic impact of underwater acoustic sources on marine animals. NUWC-NPT Technical Report 11158. Naval Undersea Warfare Center, Division Newport, RI

Lazauski CJ, Mitchell GH, Fetherston TN II (2003) Method for determining acoustic impact of underwater acoustic sources on marine animals. US Patent 6519547, The United States of America as represented by the Secretary of the Navy, Washington, DC. www.freepatentsonline. com/6519547.html (accessed 02 December 2008)

Mace BL, Bell PA, Loomis RJ (1999) Aesthetic, affective, and cognitive effects of noise on natural landscape assessment. Soc Nat Resour 12:222-242

Mace BL, Bell PA, Loomis RJ (2004) Visibility and natural quiet in national parks and wilderness areas. Environ Behav 36:5-31

Malings GC Jr (2003) An editor's view of the EPA noise program. Noise Control Eng J 51:143-150

Mann DA, Zhongmin L, Popper AN (1997) A clupeid fish can detect ultrasound. Nature 389:341

MARAD (US Maritime Administration) (2007a) United States Department of Transportation license to own, construct and operate a deepwater port issued to Northeast Gateway Energy Bridge LLC

MARAD (US Maritime Administration) (2007b) United States Department of Transportation license to own, construct and operate a deepwater port issued to Neptune LLC

McCarthy E (2004) International regulation of underwater sound: establishing rules and standards to address ocean noise pollution. Kluwer Academic Publishers, Boston, MA

McDonald CD, Baumgarten RM, Iachan R (1995) Aircraft management studies: National Park Service visitors survey. HMMH Report No. 290940.12; NPOA Report No. 94-2, National Park Service, US Department of the Interior, Washington, DC

McDonald MA, Hildebrand JA, Wiggins SM (2006) Increases in deep ocean ambient noise in the Northeast Pacific west of San Nicolas Island, California. J Acoust Soc Am 120:711-718

McKenna MF, Soldevilla M, Oleson E, Wiggins S, Hildebrand JA (2008) Increased underwater noise levels in the Santa Barbara Channel from commercial ship traffic and its potential impact on blue whales (Balaenoptera musculus). Proc 7th California Islands Symp, February 5-7, Oxnard, CA, p 45

McLeod KL, Lubchenco J, Palumbi SR, Rosenberg AA (2005) Scientific consensus statement on marine ecosystembased management. Signed by 221 academic scientists and policy experts with relevant expertise and published by the Communication Partnership for Science and the Sea. http://compassonline.org/?q=EBM (accessed 02 December 2008)

Miller NP (1982) A method for assessing automobile noise. EPA Report Number 550/9-82-405

Miller NP (2003) Transportation noise and recreational lands. Noise/News Int 11:9-21

Miller NP, Anderson GS, Horonjeff RD, Menge CW, Ross JC, Newmark M (2003) Aircraft noise validation study. Report No 295860.29. Harris, Miller, Miller, and Hanson (HMMH), Burlington, MA

Mills HG, Figueroa HK (2005) Extensible bioacoustical analysis software: two examples. J Acoust Soc Am 117:2525

MMC (US Marine Mammal Commission) (2007) Marine mammals and noise: a sound approach to research and management. A Report to the US Congress from the Marine Mammal Commission, Bethesda, MD

MMPA (US Marine Mammal Protection Act) (1972 as amended through 2007) 16 USC 86:1361-1407. www.nmfs.noaa.gov/pr/laws/MMPA/mmpatext/mmpaall. pdf (accessed 15 May 2008)

Muir J (1902) The Grand Cañon of the Colorado. Century Magazine. In: Badè WF (ed) (1918) Steep trails. Houghton Mifflin, Boston, MA

NCA (US Noise Control Act) (1972) Pub L 92-574, amended by Pub L 94-301, Pub L 95-609, Pub L 100-418

NEPA (US National Environmental Policy Act) (1969 as amended through 1982) Pub L 91-190, 42 USC 43214347, as amended by Pub L 94-52, Pub L 94-83, and Pub L 97-258, § 4(b). http://ceq.hss.doe.gov/Nepa/regs/nepa/ nepaeqia.htm (accessed 15 May 2008)

Newmark WD (1987) A land-bridge island perspective on mammalian extinctions in western North American parks. Nature 325:430-432

NMSA (US National Marine Sanctuaries Act) (1992 as amended through 2000) 16 USC 1431 et seq. http://sanctuaries.noaa.gov/library/National/NMSA.pdf (accessed 15 May 2008)

NOAA (US National Oceanic and Atmospheric Administration) (2005) Regulations governing the taking and importing of marine mammals. Subchapter C: Marine Mammal Protection Act regulations (50 CFR 216)

NOAA (US National Oceanic and Atmospheric Administration) (2007a) Policy statement on human-induced acoustic impacts on marine life. Office of National Marine Sanctuaries. http://sanctuaries.noaa.gov/management/pdfs/ nmsp_acousticspolicy.pdf (accessed 15 May 2008)

NOAA (US National Oceanic and Atmospheric Administration) (2007b) New NOAA research vessel exceeds international standards as quiet vessel. NOAA News Online (Story \#2885), June 28, 2007. www.noaanews.noaa. gov/stories2007/s2886.htm (accessed 15 May 2008)

NOAA (US National Oceanic and Atmospheric Administration) (2008) Stellwagen Bank National Marine Sanctuary 
draft management plan / Draft environmental assessment. NOAA, US Department of Commerce, Silver Spring, MD Nowacek DP, Thorne LH, Johnston D, Tyack PL (2007) Responses of cetaceans to anthropogenic noise. Mammal Rev 37:81-115

NPATMA (US National Parks Air Tour Management Act) (2000). Pub L 106-181

NPOA (US National Parks Overflight Act) (1987). Pub L 100-191

NPS (US National Park Service) (1994) Report on effects of aircraft overflights on the National Park System. Washington, DC

NPS (US National Park Service) (2000) Director's Order \#47: soundscape preservation and noise management. www.nps.gov/policy/DOrders/DOrder47.html (accessed 02 December 2008)

NPS (US National Park Service) (2006) Management policies. www.nps.gov/policy/mp/Index2006.htm (accessed 02 June 2008)

NPS (US National Park Service) (2007) Salute to service: National Park Service Director's report. US Department of the Interior, Washington, DC. www.nps.gov/archive/ 2007DirectorsReport/ (accessed 02 June 2008)

NPS (US National Park Service) (2008a) Code of regulations. Title 36: parks, forests, and public property. Chapter I. National Park Service, Department of the Interior. Part 2 (Resource protection, public use and recreation) and Part 3 (Boating and water use activities)

NPS (US National Park Service) (2008b) Grand Canyon National Park: overflights - chronology of significant events. www.nps.gov/grca/naturescience/airoverflights_ chrono.htm (accessed 12 May 2008)

NPS Organic Act (US National Park Service Organic Act) (1916) Pub L 64-235, 16 USC 1, 2-4

NRC (National Research Council of the US National Academies) (2000) Marine mammals and low-frequency sound: progress since 1994. National Academy Press, Washington, DC

NRC (National Research Council of the US National Academies) (2003) Ocean noise and marine mammals. National Academy Press, Washington, DC

NRC (National Research Council of the US National Academies) (2005) Marine mammal populations and ocean noise: determining when ocean noise causes biologically significant effects. National Academy Press, Washington, DC

NTTAA (US National Technology Transfer and Advancement Act) (1995) Pub L 104-113 Sec 12(d)

OMB (US Office of Management and Budget) (1998) Circular No. A-119: federal participation in the development and use of voluntary consensus standards and in conformity assessment activities. www.whitehouse.gov/omb/ circulars/a119/a119.html (accessed 15 May 2008)

Owen D (2003) The disappointing history of the National Marine Sanctuaries Act. NYU Environ Law J 11:711-758

Payne R, Webb D (1971) Orientation by means of long range acoustic signaling in baleen whales. Ann NY Acad Sci 188:110-141

Pew Oceans Commission (2003) America's living oceans: charting a course for sea change. A report to the nation. Pew Oceans Commission, Arlington, VA

Rabin LA, Coss RG, Owings DH (2006) The effects of wind turbines on antipredator behavior in California ground squirrels (Spermophilus beecheyi). Biol Conserv 131: 410-420

Richardson JW, Greene CR Jr, Malme CI, Thomson DH (eds) (1995) Marine mammals and noise. Academic Press, San Diego, CA

Riitters KH, Wickham JD (2003) How far to the nearest road?
Front Ecol Environ 1:125-129

Schafer RM (1993) The soundscape: our sonic environment and the tuning of the world. Destiny Books, Rochester, VT

Shapiro SA (1991) The dormant Noise Control Act and options to abate noise pollution. Report for the Administrative Conference of the US, Washington, DC

Shyu H, Hillson R (2006) A software workbench for estimating the effects of cumulative sound exposure in marine mammals. IEEE J Oceanic Eng 31:8-21

Siderius M, Houser DH (2006) Guest editorial: effects of sound on the marine environment (ESME). IEEE J Oceanic Eng 31:2-3

Skeoch A (2008) Listening earth: the pure sounds of nature. www.listeningearth.com.au/index.htm (accessed 02 May 2008)

Southall BL (2005) Shipping noise and marine mammals: a forum for science, management, and technology. Final Report of the National Oceanic and Atmospheric Administration (NOAA) International Symposium. US NOAA Fisheries, Arlington, VA. http://www/nmfs.noaa.gov/pr/ acoustics/shipnoise.htm (accessed 15 May 2008)

Southall BL, Scholik-Schlomer A (2009) Potential application of vessel-quieting technology on large commercial vessels. Final Report of the National Oceanic and Atmospheric Administration (NOAA) International Conference. US NOAA Fisheries, Silver Spring, MD

> Southall BL, Bowles AE, Ellison WE, Finneran JJ and others (2007) Marine mammal noise exposure criteria: initial scientific recommendations. Aquat Mamm 33:411-414

Spreng M (2000) Possible health effects of noise induced cortisol increase. Noise Health 2:59-64

The Mathworks (2006) MATLAB

Tyack PL (2008) Implications for marine mammals of largescale changes in the marine acoustic environment. J Mammal 89:549-558

United Nations (2008) Shipping and world trade. Atlas of the oceans. www.oceansatlas.org/unatlas/uses/transportation_telecomm/maritime_trans/worldtrade/world_trade.htm (accessed 15 May 2008)

US Air Tour Association v Federal Aviation Administration (2002) DC Cir 298 F 3d 997

US Census Bureau (2008) National and state population estimates. www.census.gov/popest/states/NST-pop-chg.html (accessed 02 December 2008)

USCG (US Coast Guard) (2006a) Final environmental impact statement. Northeast Gateway Deepwater Port Project. \#USCG-2005-22219

USCG (US Coast Guard) (2006b) Final environmental impact statement. Neptune LNG Deepwater Port Project. \#USCG-2005-22611

US Commission on Ocean Policy (2004) An ocean blueprint for the 21st century. Final Report, Washington, DC

US Department of Commerce Office of Inspector General (2008) National Marine Sanctuary Program protects certain resources, but further actions could increase protection. Final Inspection Report No. IPE-18591/February 2008

US Department of Transportation Act (1966 as amended through 1968) Declaration of Purpose and Section 4(f), Pub L 89-670, 49 USC 303 (formerly 49 USC 1651(b)(2) and 49 USC.1653f), amended by Pub L 90-495 and Pub L 97-449

US Federal Highway Administration (2008) Historical monthly VMT report. www.fhwa.dot.gov/policyinformation/travel/tvt/history/ (accessed 02 December 2008)

US Federal Register (2003) Automatic identification system; vessel carriage requirement. US Coast Guard, Department of Homeland Security. October 22 2003: 60559-60570 
US Federal Register (2008) Public notice: clarifying the definition of 'substantial restoration of natural quiet' at Grand Canyon National Park, Arizona. US National Park Service, Department of the Interior. 09 April 2008:19246-19248

US Ocean Action Plan (2004) The Bush Administration's response to the US Commission on Ocean Policy. http:// ocean.ceq.gov/actionplan.pdf (accessed 02 December 2008)

US Presidential Executive Order 13158 (2000) Executive Order on Marine Protected Areas (MPAs). Signed by President Clinton 26 May

Van Parijs SM, Southall BL (2007) Report of the 2006 NOAA National Passive Acoustics Workshop. NOAA Technical Memorandum NMFS-F/SPO-81. NOAA Fisheries, Woods Hole, MA

Van Parijs SM, Clark CW, Sousa-Lima RS, Parks SE, Rankin S, Risch D, Van Opzeeland IC (2009) Mesoscale applications of near real-time and archival passive acoustic

Submitted: June 3, 2008; Accepted: January 26, 2009 arrays. Mar Ecol Prog Ser 395:21-36

Vitousek PM, Mooney HA, Lubchenco J, Melillo JM (1997) Human domination of earth's ecosystems. Science 277: 494-499

Wartzok D, Ketten DR (1999) Marine mammal sensory systems. In: Reynolds JE II, Rommel SA (eds) Biology of marine mammals. Smithsonian Institution Press, Washington, DC, p 117-175

Weilgart L (2006) Managing noise through marine protected areas around global hot spots. Int Whaling Comm SC/58/E25

Weinberg H, Deavenport RL, McCarthy EH, Anderson CM (2001) Comprehensive Acoustic System Simulation (CASS) reference guide. NUWC-NPT Technical Memo 01016, Naval Undersea Warfare Center, Division Newport, RI

Wright AJ, Soto NA, Baldwin AL, Bateson $\mathrm{M}$ and others (2007) Anthropogenic noise as a stressor in animals: a multidisciplinary perspective. Int J Comp Psychol 20: 250-273

Proofs received from author(s): May 18, 2009 